\title{
Relationship of Endogenous ABA and IAA to Accumulation of Grain Protein and Starch in Two Winter Wheat Cultivars under Post-anthesis Water Deficit
}

\author{
Saeed Saeedipour (Corresponding author) \\ Department of Agronomy, Shoushtar Branch, Islamic Azad University, Shoushtar, Iran \\ E-mail: saeeds79@gmail.com
}

Foad Moradi

Agriculture Biotechnology Research Institue, Karaj, Iran

E-mail: foadmoradi@yahoo.com

Received: June 27, 2011

Accepted: July 12, $2011 \quad$ Online Published: December 21, 2011

doi:10.5539/jas.v4n2p147

URL: http://dx.doi.org/10.5539/jas.v4n2p147

\begin{abstract}
Accumulation of protein and starch in grain is a key process determining grain yield and quality in wheat. Under drought endogenous plant hormone levels will change and may have an impact on the yield and quality of wheat. In a greenhouse experiment, two winter wheat (Triticum aestivum L.) varieties differing in post anthesis drought resistance, tolerant (cv. Zagros) and sensitive (cv. Marvdasht), were subjected to either well-watered (WW) or water-stressed (WS) from anthesis to maturity. On the 7, 15 (grain enlargement stage) and 31 (grain filling stage) days after anthesis (DAA), endogenous abscisic acid (ABA) and indole-3-acetic acid (IAA) were determined in grain of wheat plants by enzyme linked immunosorbent assay (ELISA). The patterns of hormonal changes were similar in two varieties. The ABA levels were much higher under water deficit than well water treatment. In comparison grain ABA levels in all sampling stages was more in Marvdasht than Zagros. The endogenous grains IAA content display a marked reduction by the time and the water stress aggravated this reduction in both cultivars, however, the depresstion was more in drought-sensitive than drought-tolerant. The relationship between yields and contents of starch and protein in grains and levels of two hormones in sink organ indicated that the changes in yield and content of grain starch and protein under water withholding were associated with the reduced IAA and elevated ABA level in grains. It was proposed that the changed levels of endogenous hormones under drought post-anthesis might indirectly affect protein and starch accumulation in grains by influencing the regulatory enzymes and processes.
\end{abstract}

Abbreviations: ABA - abscisic acid, DAA - Days after-anthesis, ELISA - enzyme linked immunosorbent assay, IAA - indole-3-acetic acid

Keywords: Drought, Endogenous hormones, Grain protein, Grain starch, Winter wheat (Triticum aestivum L.)

\section{Introduction}

Plant growth and development can be inhibited by water stress at any time in crop life cycles, but the sensitivity to water stress is particularly acute during the reproductive development, because reproduction involves several processes that are extremely vulnerable to a change in plant water status. Grain yield of wheat (Triticum aestivum L.) is finally determined after anthesis, the yield potential and superior grain quality are two major goals in cereal production. Yet it is difficult to achieve these two goals simultaneously due to the interaction of genetic and environmental factors (Terman, 1979). During the post-anthesis senescence, plant nitrogen metabolism plays an essential role in grain protein accumulation, which is a major determinant of overall grain quality. Yet most studies about phytohormonal regulation of ABA and IAA in the transportation and distribution of assimilates have concentrated on carbohydrates, although sufficient evidence reveals that different exogenous phytohormones serve as modulators of specific rate limiting components in photoassimilate metabolism (Brenner and Cheikh, 1995). During grain development, appropriate soil water status is of key importance for 
accumulation of starch and protein in grains and thus formation of grain yield and quality (Ahmadi and Baker, 2001). Previous studies have shown that endogenous hormones are essential regulators for translocation and partitioning of photoassimilates for grain filling in cereal crops, and therefore could be involved in the regulation of grain weight and yield (Ahmadi and Baker, 1999; Brenner and Cheikh, 1995; Darussalam Cole and Patrick, 1998; Wang et al., 1999). With deficit soil water endogenous hormones act as responding signals (Bano et al., 1993; Davies et al., 1986; Jackson et al., 1988) and thus may play important roles in the growth and development processes, including synthesis and accumulation of starch and protein in grains. Understanding this issue may guide regulation of grain quality formation in wheat by exogenous application of growth substances.

Generally, ABA increases markedly under drought (Bano et al., 1993; Davies et al., 1986; Hein et al., 1986), yet IAA changes inconsistently (Davies et al., 1986; Yuan and Ding, 1990). However, observed effects of ABA on the capacity of the sink to accumulate dry matter are not consistent; both inhibition and stimulation have been reported. The increase in ABA levels towards the end of grain filling and its rapid fall during maturation have raised questions about the role of ABA in controlling dry matter accumulation (Bewley and Black, 1994; Kermode et al., 1989; King, 1982). Indeed in several cases the application of ABA to the medium has enhanced accumulation of reserves, particularly storage proteins in legumes, and production of mRNA (Kermode et al., 1989). Stimulatory effects of ABA on assimilate unloading (Schussler, 1984; Tanner, 1980) and in vitro sucrose uptake (Brenner et al., 1986; Schussler, 1984) have also been reported. Nevertheless, these promoting effects are not always observed, and depending on the concentration and the timing of ABA application, inhibitory effects may predominate. Ahmadi and Baker (1999) have demonstrated that the translocation and conversion of sucrose within the grains of ears cultured in vitro is inhibited by the high concentration of ABA $(0.1 \mathrm{mM})$, but is stimulated by the lower concentration $(1 \mu \mathrm{M})$. It has been proposed that $\mathrm{ABA}$ reduces grain yield by sealing the conducting tissues, accelerating grain water loss and affecting starch synthesizing enzymes (Radley, 1976). IAA is also a factor stimulating assimilate transport to developing grains (Darussalam et al., 1998). The objectives of the present study were to characterize endogenous hormone levels in sink organ of wheat varieties with different properties under post-anthesis drought to determine the relationships between the hormonal levels in plants and protein and starch accumulation in grains.

\section{Material and Method}

\subsection{Plant materials and soil water treatments}

Based on preliminary experiments (Saeidi et al., 2006), two contrasting winter wheat cultivars (Triticum aestivum L.) Marvdasht and Zagros (drought susceptible and tolerant during grain filling, respectively were used in pot culture experiments during the growing season from 2009 to 2010 in the greenhouse of Agricultural Biotechnology Research Institute of Iran $\left(48^{\circ} 20 \mathrm{~N} ; 31^{\circ} 41 \mathrm{E} ; 20 \mathrm{~m}\right.$ above sea level). Pots with a diameter of $23 \mathrm{~cm}$ and height of $25 \mathrm{~cm}$ were each filled with $8 \mathrm{~kg} \mathrm{pot}^{-1}$ sieved yellow drab soil mixed with $20 \mathrm{~g} \mathrm{pot}^{-1}$ manure fertilizer and $3.3 \mathrm{~g} \mathrm{pot}^{-1}$ compound fertilizer ( $\left.\mathrm{N}: \mathrm{P}: \mathrm{K}=9: 8: 8\right)$. The soil contained organic matter of $1.48 \%$, total $\mathrm{N}$ of $0.12 \%$, available $\mathrm{N}$ of $82.3 \mu \mathrm{g} \mathrm{g}^{-1}$, available $\mathrm{P}_{2} \mathrm{O}_{5}$ of $30.9 \mu \mathrm{g} \mathrm{g}^{-1}$, available $\mathrm{K}_{2} \mathrm{O}$ of $126.7 \mu \mathrm{g} \mathrm{g}^{-1}$. Fifteen seedlings per pot were may grown at the beginning, and then thinned to five per pot at the third-leaf stage. From 1 days post-anthesis (DPA) to maturity two soil water treatments were implemented by daily water compensation with respect to the weight decrease of each pot, i.e. soil relative water content (SRWC) at $45 \sim 50 \%$ as water stress (WS), at $75 \sim 80 \%$ as well water (WW). The experiment was $2 \times 2$ (two cultivars and two water regimes) factorial design with four treatment. Each of the treatment had four replications with three sub-samples, in a complete randomized block design.

Twenty to fifteen plants from each treatment were sampled at 7,15 and 31 days after anthesis. The second and third kernel from each spikelet were frozen in liquid nitrogen for $1 \mathrm{~min}$ and stored at $-80^{\circ} \mathrm{C}$ for enzymatic assay. From each treatment 20 plants were harvested at maturity for the determination of grain yield, protein and starch contents. Each measurement was done on plants from four different pots.

\subsection{Assay of endogenous hormones}

The detailed procedures for extraction and purification of plant hormones prior to immunoassay have been described in Cao et al., (2000). Extraction of homogenized samples was conducted in cold $80 \%(\mathrm{~V} / \mathrm{V})$ aqueous methanol at a rate of $5 \mathrm{ml} / \mathrm{g} \mathrm{FW}$ overnight at $4{ }^{\circ} \mathrm{C}$. The supernatant was collected after Centrifugation at $10000 \mathrm{~g}$ $\left(4{ }^{\circ} \mathrm{C}\right)$ for $20 \mathrm{~min}$. Then the crude extract was passed through a $\mathrm{C}_{18}$ Sep-Pak catridge (Waters, Milford, MA). The efflux was collected, $500 \mathrm{ml}$ was taken out and dried with a stream of $\mathrm{N}_{2}$, and the residue was dissolved in 200 $\mathrm{ml}$ of PBS (0.01 mol $\left.\mathrm{l}^{-1}, \mathrm{pH} 9.2\right)$, adjusted to $\mathrm{pH} 8.5$, then partitioned with an equal volume of ethyl acetate three times. The remaining water phase was adjusted to $\mathrm{pH} 2.5$ and extracted with an equal volume of ethyl acetate three times. The extracts (ethyl acetate phase) were pooled and dried with a gentle stream of $\mathrm{N}_{2}$. The residue was 
redissolved in $200 \mu \mathrm{l}$ of $100 \%$ methanol for methylation with freshly synthesized ethereal diazomethane and taken up with $400 \mathrm{ml}$ of PBS for IAA and ABA ELISAs, respectively. The procedures for direct ELISA measurement based on monoclonal antibodies against ABA, and indirect ELISA measurements using polyclonal antibodies against IAA were described by Chen et al., (1996). Both direct and indirect ELISAs were performed with microtitration plates (Nunc.). Each hormone was assayed in triplicates.

\subsection{Assay of grain starch and protein}

Starch in grains was determined in the glucose-free residue left after $\mathrm{HCl}$ treatment (Ling and Zhu, 1999). After addition of $5 \mathrm{ml}$ of $\mathrm{HCl}\left(0.33 \mathrm{~mol} \mathrm{l}^{-1}\right), 1 \mathrm{~g}$ of grain powder was kept in a boiling water bath for $10 \mathrm{~min}$ and $0.5 \mathrm{ml}$ of $30 \%(\mathrm{~m} / \mathrm{v}) \mathrm{ZnSO}_{4}$ was added and mixed thoroughly to deposit the grain protein from cooled $\mathrm{HCl}$ reaction mixtures, then $0.5 \mathrm{ml}$ of $30 \%(\mathrm{~m} / \mathrm{v}) \mathrm{K}_{3}\left[\mathrm{Fe}(\mathrm{CN})_{6}\right]$ was added and mixed by shaken. The reaction mixtures were adjusted to a volume of $20 \mathrm{ml}$, then shaken up and filtrated. Starch was then hydrolyzed completely into glucose, which was determined by an automatic recording polarimeter (SPOIFWZZ-2A, China) using polarimetric analysis at $20-25{ }^{\circ} \mathrm{C}$. Starch content was calculated as: Starch content $(\%)=[(20 \times \alpha) / \alpha \mathrm{D} \times L \times M(1-H)] \times 100$ where $\alpha$ means polarimetry degree, 20 is the total volume of sample solution $(\mathrm{ml}), M$ is sample weight $(\mathrm{g}), L$ is the length of polarimetry tube $(\mathrm{dm}), H$ is humidity of powder, $\alpha_{\mathrm{D}}$ is the ratio of polarimetry to degree of starch, which is set at 182.7 in wheat. Total $\mathrm{N}$ in grains was determined by the semi micro Kieldahl method (AOAC, 1984). Multiplying $\mathrm{N}$ content by 5.7 gave the protein content in grains.

\section{Results}

\subsection{Endogenous hormone levels in grains}

A comparison between ABA levels of water stressed grains and that of the control clearly indicated the response of this hormone to water stress. Under water limited condition, ABA content in grains of two varieties increased significantly (Figure 1). Water stress rose substantially the ABA level during the 7 days from anthesis; during the subsequent periods ( 7 to $15 \mathrm{DAA}$ ); the differences between ABA content treatments was barely detectable in both cultivars (Figure 1), but after 31 days from anthesis, ABA concentration in water stressed increased markedly, as the values achieved to $101 \%$ and $72 \%$ in Marvdasht and Zagros respectively, contrast to their respective controls (Figure 1).

The amounts of grains IAA content reduced sharply with time in both treatments during 7 to 15 DAA (Figure 2), although, considerable differences were detected between treatments, as substantial reduction occurred in both cultivars under water stress compared with the control treatment. Irrespective of treatment, Marvdasht revealed higher IAA content than Zagros throughout all stages sampling. Reduction in IAA concentration in drought-sensitive genotype under WS was more remarkable than drought-tolerant during 7 days after anthesis; as the reduction was $72 \%$ and $20.6 \%$ in respective to those control in Marvdasht and Zagros, respectively. After 15 days from anthesis, a substantial reduction (72\%) in IAA concentration was followed by slight, but significant statically reduction at day 31 observed in Marvdasht (Figure 2), whereas in Zagros, the reduction was $52 \%$ at day 15 under WS contrast to WW treatment, and no significant difference in IAA level was observed between the water-stressed Zagros cultivar and the controls at day 31 (Figure 2).

\subsection{Effects of different soil water status contents on grain protein and starch}

Regardless of water regime treatments the pattern of starch accumulation was similar in both cultivars. The peak values for grain starch were gained at 15 DAA in two cultivars, however, the amount of starch accumulation in Marvdasht was 2 fold more than Zagros at that time under WW treatment. From 15 to 31 DAA, grain starch content decreased with a sharp slop in Marvdasht, where as the differences between two sampling dates (15 and 31 DAA) in Zagros was negligible (Figure 3). The water stress resulted in a significant reduction in grain starch content quite all stages sampling of Marvdasht cultivar (Table 1). Reduction in grain starch concentration in drought-sensitive cultivar was more remarkable, since this reduction was not evident throughout experiment in Zagros (Figure 3). Irrespective of water deficit grain protein content were decreased in both cultivars from day 7 onwards, and the reduction became more pronounced with time, however Zagros revealed higher grain protein at early stage of developing grain, as the values achieved to 27.35 and $15.65 \mathrm{mg} \mathrm{g}^{-1} \mathrm{Fw}$ at 7 and 15 DAA while these values reached to 15.65 and $6.45 \mathrm{mg} \mathrm{g}^{-1} \mathrm{FW}$ in Marvdasht at the same sampling stages. Results from the all sample stage except for day 7 showed that, the grain protein content was enhanced when the water stress was imposed, however, the increment was more in drought-sensitive cultivar than drought tolerant one, as the mean levels on days 15 and 31 elevated $138.7 \%$ and $88 \%$ in Marvdasht compare to $18.98 \%$ and $40 \%$ at the same sampling stages in Zagros (Table 1). 


\subsection{Kernel weight and grain yield}

Water stress resulted in a drastic reduction in Marvdasht kernel weight, whereas no significant reduction observed in Zagros cultivar (Figure5-B). The reduction percentage in Marvdasht (50.6\%) was higher than Zagros $(11.2 \%)$ under stress regime. A similar changing pattern found for grain yield and grain number per spike, however, the reduction for both traits statically was significant in Zagros under water deficit (Figure5 A\&C). In contrast, the reduction percentage of grain yield (8.4\%) and kernel number $(10 \%)$ per Zagros spike were lower than that of Marvdasht (45.5\% and 20\%). These indicate that water deficits during the days after anthesis control the grain yield mainly by influencing kernel weight rather than the spike.

\section{Discussion}

The ABA level of water stressed grains showed a substantial increase during all sampling stage in both cultivar. Although, irrespective of treatment the ABA level of Marvdasht grains remained higher than Zagros Cultivar (Figure 1). An increase in grain ABA content with an increase in grain weight is taken as an indication of the involvement of ABA in grain development (Bewley and Black, 1994; Kermode et al., 1989; King, 1982).Although endogenous ABA level in grains usually increases rapidly during the grain filling process in cereals, the extremely high and continuing endogenous ABA levels under drought may have inhibitory effects on grain growth (Ahmadi and Baker, 1999) and yield formation. In rice grown under drought, ABA concentrations in leaves and grains increased markedly, which inhibited the grain growth partly through inhibiting sucrose synthase (Kermode et al., 1989; Liang et al., 1996). In maize, decreased rate of endosperm cell division induced by water stress was attributed to elevated levels of ABA (Ober et al., 1991). The ABA concentration during early (15 DAA) and late (31 DAA) stage of water stress in Marvdasht were 2 and 1.2 fold higher than Zagros cultivar. These results support the proposal that elevated ABA levels induced by drought are unfavorable for starch accumulation and yield formation in wheat grains Marvdasht than Zagros cultivar. A slight stimulatory effect of low ABA concentrations in drought-resistance and an inhibitory effect of high ABA concentrations in drought-sensitive on grain weight by grains dry mass accumulation was observed. In our experiment, under water stress obvious differences between genotypes for grain weight were found, as the reduction were $50.2 \%$ and $9 \%$ contrast to those control treatment in Marvdasht and Zagros, respectively (Figure 5-B). It is noteworthy that the grain number per spike, versus grain weight fewer influenced under water deficit in both cultivar. Therefore, it seems that the reduced grain weight under water stress conditions indicate the inhibitory effect of $\mathrm{ABA}$ on reserve deposition effect.

Such a concentration dependent stimulatory/inhibitory effect of ABA has been reported on assimilate import by barley grains (Tietz et al., 1981) and growth of tomato plants (Takahashi et al., 1993). The effect of ABA on total sucrose uptake can be either direct, acting via the uptake mechanism, or indirect by altering sucrose conversion inside the cells and thus controlling the sucrose movement through diffusional mechanisms. ABA stimulates the accumulation of sucrose in a range of tissues and a correlation has been observed between dry matter accumulation and endogenous ABA levels in the sink regions of some plant species (Thomas, 1986). In vitro sucrose uptake by soybean cotyledons, for instance, was enhanced by low ABA concentrations and was correlated with the endogenous ABA levels (Takahashi et al., 1993). The stimulatory effects of ABA application into the culture medium of soybean cotyledons disappeared when endogenous ABA content of the cotyledons increased due to in situ growth conditions (Schussler et al., 1984). If ABA decreases the ATPase proton extrusion (Tanner, 1980) a reduced proton cotransport of sucrose into the endosperm cells would result. A part from the effect at the site of uptake, ABA at high concentrations reduced the conversion of sucrose to starch whereas at low concentrations such an effect was not evident. The site of ABA action in this respect appears to be one or more of the key enzymes of starch synthesis (Radley, 1976). In comparison, the inhibitory effects of ABA on the growth of Marvdasht kernels observed here and of maize kernels (Myers et al., 1990) imply a specific role for $\mathrm{ABA}$ in growth and related regulatory parameters and maybe not in assimilate import.

In the literatures, it has also been suggested that the enhanced ABA levels favored grain growth in some cases, gene expression in rape and alfalfa (Jackson et al., especially in storage protein accumulation and its mRNA production in legumes and storage protein 1988; Wilen et al., 1990; Xu and Bewley, 1995). On basis of our present study increased Marvdasht grain ABA content was simultaneous with higher protein accumulation, that means the higher ABA level of Marvdasht grains caused to more protein content compare to Zagros. Integrating the present results and previous reports (Xie et al., 2003), in wheat, it may be concluded that enhanced endogenous ABA level generally increases protein content in droughted wheat.

It has been reported that IAA level in wheat grains reached maximum at the grain filling stage, and played an important role in regulation of grain filling (Brenner and Cheikh, 1995). In our study, we found the peak of IAA 
level of control grains at early stage of grain development (during 7 DAA), and the accumulation decreased by the time in both cultivar (Figure 2). Water stress aggravated the reduction of IAA during the 15 days from anthesis; and the reduction was more pronounced in Marvdasht than Zagros. The result here indicate the inhibitory effect of low IAA concentration on cell division period processes. The concentration of IAA in drought-sensitive was considerably lower than drought-resistance in water stressed grains during enlargement stage (15 DAA). Thus, the limited effect of IAA on grain growth lead to bigger loss yield in Marvdasht than Zagros resulted in reduce grain weight. The positive effects of IAA on photoassimilate translocation within developing wheat grains have also been reported in other studies (Bangerth et al., 1985; Darussalam Cole and Patrick, 1998). These results are consonant with the present study, indicating that IAA may be involved in regulation of starch production in grains. The relationship between the IAA levels and accumulation of starch and protein in grains was positive and negative, respectively. This may be caused by the fluctuation of IAA level during the grain growth period, in which IAA reached a maximum at the grain enlargement stage, but was reduced at the grain filling stage. The fact that IAA can be transported from its source organs to leaves by the long distance transport system within the plant (Hein et al., 1986), raises the possibility that auxin transport could be reduced by water deficit (Davies et al., 1986). In addition, since the high level of plant IAA can lead to the enhancement of ethylene synthesis (Mckeon and Yang, 1988), the advanced emergence of the IAA maximum under drought at grain enlargement stage may be related to the stress-induced shortening in grain-filling period and the acceleration of plant senescence. Because of the complex interaction among different hormones, the balance of endogenous hormone levels can provide further insight into the relationships of endogenous hormones to grain protein and starch accumulation under different post-anthesis soil water statusses. There is much evidence that endogenous hormones, to a great extent, regulate the activities of key enzymes for starch synthesis and accumulation in cereal grains such as SPS, ADPGPase and FBPase, which are involved in photoassimilate production, translocation, phloem loading and compartmentation (Brenner and Cheikh, 1995). Ahmadi and Baker (2001) indicated that the marked reduction in the starch and sucrose contents of grains under water deficit was related to the activity changes in key regulatory enzymes from the sucrose to starch pathway in wheat such as SS, SSS, GBSS, UDPG and ADPG (Ahmadi and Baker, 2001).

\section{Conclusion}

In conclusion, the changes in grain yield, starch and protein content in grains under drought were closely associated with the reduced levels of endogenous IAA and elevated level of ABA in grains wheat plant. The changes of endogenous hormone levels under water stress may indirectly affect protein and starch accumulation in grains via influencing the related enzymes and processes. While the possible regulation mechanisms of endogenous hormone in nitrogen remobilization and distribution to grain and its relations to related enzymes in grain protein accumulation require further investigation.

\section{Acknowledgement}

The corresponding author gratefully acknowledges the funding from the Islamic Azad University, Shoushtar branch through Grant.

\section{References}

Ahmadi, A. \& Baker, D.A. (1999). Effects of abscisic acid (ABA) on grain filling processes in wheat. Plant Growth Regulation, 28, 187-197. http://dx.doi.org/10.1023/A:1006223925694

Ahmadi, A. \& Baker, D.A. (2001). The effect of water stress on the activities of key regulatory enzymes of the sucrose to starch pathway in wheat. Plant Growth Regulation, 35, 81-91. http://dx.doi.org/10.1023/A:1013827600528

AOAC. (1984). Official Methods of Analysis. 14th edn. Association of Official Analytical Chemists, Arlington, VA, USA.

Bangerth, F., Aufhammer, W. \& Baum, O. (1985). IAA level and dry matter accumulation at different positions with a wheat ear. Physiology Plant, 63, 121-125. http://dx.doi.org/10.1111/j.1399-3054.1985.tb02829.x

Bano, A., Dorffling, K., Bettin, D. \& Hahn, H. (1993). Abscisic acid and cytokinins as possible root-to-shoot signals in xylem sap of rice plants in drying soils. Australian Journal of Plant Physiology, 20, 109-115. http://dx.doi.org/10.1071/PP9930109

Bewley, J.D. \& Black, M. (1994). Seeds Physiology of Development and germination, Second Edition. NewYork and London: Plenum Press. 
Brenner, M.L. \& Cheikh, N. (1995). The role of hormones in photosynthate partitioning and seed filling. In: Davies P.J. (eds), Plant Hormones. Kluwer Academic Publishers, The Netherlands, 649-670. http://dx.doi.org/10.1007/978-94-011-0473-9_30

Brenner, ML., Brun, W.A., Schussle, J. \& Cheikh, N. (1986). Effects of endogenous and exogenous plant growth substances on development and yield of soybeans. In: Bopp M (ed) Plant Growth Substances. Berlin Heidelberg: Springer-Verlag, 380-386.

Cao, W.X., Wang, Z.L. \& Dai, T.B. (2000). Changes in levels of endogenous plant hormones during floret development in wheat genotypes of different spike sizes. Acta Botany Sinica, 42 (10), 1026-1032.

Chen, J.G., Du, X.M., Zhao, H.Y. \& Zhou, X. (1996). Fluctuation in levels of endogenous plant hormones in ovules of normal and mutant cotton during flowering and their relation to fiber development. Journal of Plant Growth Regulation, 15, 173-177. http://dx.doi.org/10.107/BF00190581

Darussalam, M., Cole, M.A. \& Patrick, J.W. (1998). Auxin control of photoassimilate transport to and within developing grains of wheat. Australian Journal of Plant Physiology, 25, 69-77. http://dx.doi.org/10.1071/PP97080

Davies, W.J., Metcalfe, J., Lodge, T.A. \& Costa, A.R. (1986). Plant growth substances and the regulation of growth under drought. Australian Journal of Plant Physiology, 13, 105-125.

Hein, M.B., Brenner, M.L. \& Brun, W.A. (1986). Accumulation of 14C-radiolabel in leaves and fruits after injection of 14Ctryptophan into seed of soybean. Plant Physiology, 82, 454-456. http://dx.doi.org/10.1104/pp.82.2.454

Jackson, M.B., Young, S.F. \& Hall, K.C. (1988). Are roots a source of abscisic acid for the shoots of flooded pea plants? Journal of Experimental Botany, 39, 1631-1637. http://dx.doi.org/10.1093/jxb/39.12.1631

Kermode, A.R, Oishi, M.Y. \& Bewley, J.D. (1989). Regulatory roles for desiccation and abscisic acid in seed development: A comparison of the evidence from whole seeds and isolated embryos. In: Stanwood PC and McDonald MB (eds) Seed Moisture. CSSA Special Publication, 23-50.

King, R.W. (1982). Abscisic acid in seed development. In: Khan AA (ed) The Physiology and Biochemistry of Seed Development, Dormancy and Germination. Elsevier Biomedical Press, 157-181.

Liang, J.S., Cao, X.Z. \& Zhu, Q.S. (1996). Abscisic acid may involve in the regulation of grain filling in water stressed rice. Chinese Journal of Rice Science, 10 (1), 29-36.

Ling, R.H. \& Zhu, Z.W. (1999). The assay methods of starch, amylopectin and amylose (In Chinese). In: The Institute of Plant Physiol. of CAS and the Plant Physiol. Society of Shanghai (eds), Guide on Modern Plant Physiology Experiments. Science, Press, Beijing, 154-158.

Mckeon, T.A. \& Yang, S.F. (1988). Biosynthesis and metabolism of ethylene In: Davies P.J. (ed.), Plant Hormones and their Role in Plant Growth and Development. Kluwer Academic Publishers, Dordrecht, 94-112.

Myers, P.N., Setter, T.L., Madison, J.T. \& Thompson, J.F. (1990) Abscisic acid inhibition of endosperm cell division in cultured maize kernels. Plant Physiology, 94,1330-1336. http://dx.doi.org/10.1104./pp.94.3.1330

Ober, E.S., Setter, T.L., Madison, J.T., Thompson, J.F. \& Shapiro, P.S. (1991). Influence of water deficit on maize endosperm development. Enzyme activities and RNA transcriptions of starch and zein synthesis, abscisic acid, and cell division. Plant Physiology, 97, 154-64. http://dx.doi.org/10.1104/pp.97.1.154

Radley, M. (1976). The development of wheat grain in relation to endosperm growth substances. Journal of Experimental Botany, 27,1009-1021. http://dx.doi.org/10.1093/jxb/27.5.1009

Saeidi, M., Moradi, F., Ahmadi, A., Poostini, K. \& Najafian, G. (2006). Effect of exogenous application of ABAand CK at different stages of grain development on some physiological aspects of source and sink relationship in two bread wheat cultivars. Iranian Journal of Crop Sciences, 8, 268-282.

Schussler, J.R., Brenner, M.L. \& Brun, W.A. (1984). Abscisic acid and its relationship to seed filling in soybeans. Plant Physiology, 76, 301-306. http://dx.doi.org/10.1104/pp.76.2301

Takahashi, H., Koshio, K., \& Ota, Y. (1993). Effects of ABAapplication to the culture solution on the growth, water relations and temperature stress in tomato plants. Journal of Japan Society Horticulture Science, 62, 389-397. http://dx.doi.org/10.2503/jjshs.62.389

Tanner, W. (1980). On the possible role of ABA on phloem unloading. Ber Deut Bot Gesel, 93, 349-351. 
Terman, G.L. (1979). Yield and protein content of wheat grain as affected by environmental growth factors. Agronomy Journal, 71, 436-446. http://dx.doi.org/10.2134/agronj1979.00021962007100030014x

Thomas, T.H. (1986). Hormonal control of assimilate movement and compartmentation. In: Bopp M (ed) Plant Growth Substances. Berlin Heidelberg: Springer-Verlag, 350-359.

Tietz, A., Ludewig, M., Dingkuhn, M. \& Dörffling, K. (1981). Effect of abscisic acid on the transport of assimilates in barley. Planta, 152, 557-561. http://dx.doi.org/10.1007/BF00380827

Wang, R.Y., Yu, Z.W. \& Pan, Q.M. (1999). Changes of endogenous plant hormone contents during grain development in wheat. Acta Agronomy Sinica, 25(3), 227-231.

Wilen, R.W., Mandel, R.M., Pharis, R.P., Holbrook, L.A. \& Moloney, M.M. (1990). Effect of abscisic acid and high osmoticum on storage protein gene expression in microspore embryos of Brassica napus. Plant Physiology, 94, 875-881. http://dx.doi.org/10.1104/pp.94.3.875

Xie, Z., Jiang, D., Cao, W., Dai, T. \& Jing, Q. (2003). Relationships of endogenous plant hormones to grain protein and starch accumulation in winter wheat under different postanthesis soil water status. Plant Growth Regulation, 41, 117-127. http://dx.doi.org/10.1023/A:1027371906349

$\mathrm{Xu}, \mathrm{N}$. \& Bewley, J.D. (1995). Temporal and nutritional factors modulate responses to abscisic acid and osmoticum in their regulation of storage protein synthesis in developing seeds of alfalfa. Journal of Experimental Botany, 46, 675-686. http://dx.doi.org/10.1093/jxb/46.6.675

Yuan, C.X. \& Ding, J. (1990). Effects of water stress on the content of IAA and the activities of IAA oxidase and peroxidase in cotton leaves. Acta Phytophysiol Sinica, 16, 179-183.

Table 1. Effect of water deficit (WS) from anthesis to maturity on endogenous grain ABA, IAA, starch and protein content, in two wheat cultivars

\begin{tabular}{|c|c|c|c|c|c|}
\hline \multicolumn{6}{|c|}{$\begin{array}{l}\% \text { Decrease }(-) / \text { increase }(+) \\
\text { respective to those control treatment }\end{array}$} \\
\hline Cultivars & $\begin{array}{l}\text { Days after } \\
\text { anthesis }\end{array}$ & $\begin{array}{c}\mathrm{ABA} \\
\left(\mu \mathrm{g} \mathrm{g}^{-1} \mathrm{Fw}\right)\end{array}$ & $\begin{array}{c}\text { IAA } \\
\left(\mu \mathrm{g} \mathrm{g}^{-1} \mathrm{Fw}\right)\end{array}$ & $\begin{array}{c}\text { Starch } \\
\left(\mathrm{mg} \mathrm{g}^{-1} \mathrm{Fw}\right)\end{array}$ & $\begin{array}{c}\text { Protein } \\
\left(\mathrm{mg} \mathrm{g}^{-1} \mathrm{Fw}\right)\end{array}$ \\
\hline \multirow{3}{*}{ Marvdasht } & 7 & $+82^{\times x}$ & $-70.2^{x \times}$ & $-56.6^{\times x}$ & $+6^{\mathrm{ns}}$ \\
\hline & 15 & $+68^{x x}$ & $-73.3^{x \times}$ & $-43.7^{\times \times}$ & $+138.7^{\times \times}$ \\
\hline & 31 & $+40^{\times x}$ & $-70^{\times \times}$ & $-52.1^{\times x}$ & $+88^{\times x}$ \\
\hline \multirow{3}{*}{ Zagros } & 7 & $+36^{\times x}$ & $-20.1^{\times}$ & $+9.4^{\mathrm{ns}}$ & $-0.4^{\mathrm{ns}}$ \\
\hline & 15 & $+45^{\text {×x }}$ & $-58.4^{\times}$ & $-7.4^{\mathrm{ns}}$ & $19^{\times}$ \\
\hline & 31 & $+14^{\times}$ & $-41.5^{\mathrm{ns}}$ & $-15.9^{\mathrm{ns}}$ & $+40^{\times}$ \\
\hline
\end{tabular}

Symbol of ${ }^{\times \times \times}$and $^{\text {ns }}$ represent of statistical significance at $p_{0.05}, 0.01$ and non significant. 

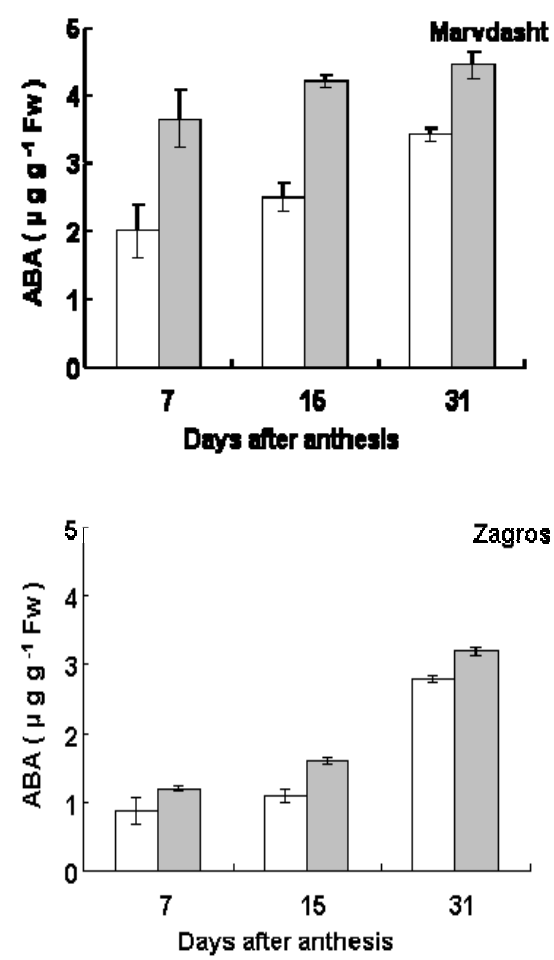

Figure 1. Effect of water stress on the abscisic acid (ABA) content of wheat grain. Water stress commenced at anthesis at $50 \%$ of field capacity level. Data are means of four replicates each consisting of six grains from the middle part of each ear. Bars indicate SEM; open columns, control; solid columns, water stressed
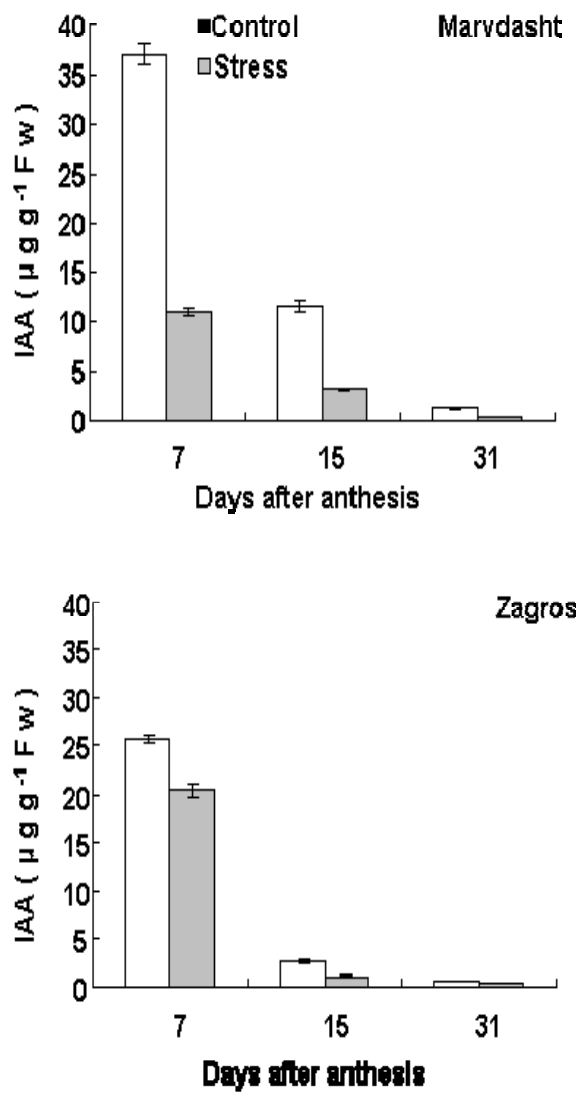

Figure 2. Effect of water stress on the indol acetic acid (IAA) content of wheat grain. Water stress commenced at anthesis at $50 \%$ of field capacity level. Data are means of four replicates each consisting of six grains from the middle part of each ear. Bars indicate SEM; open columns, control; solid columns, water stressed 

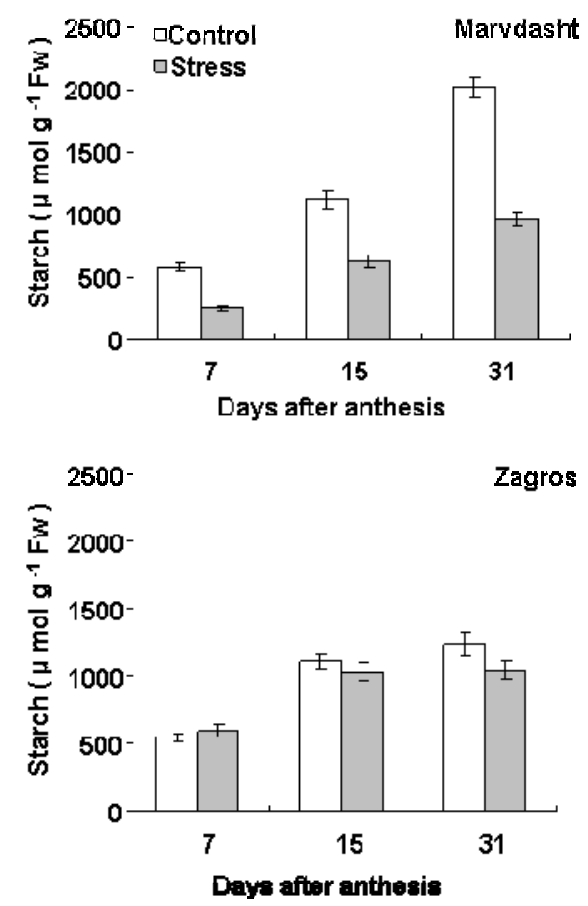

Figure 3. Effect of water stress on starch content of wheat grain. Water stress commenced at anthesis at $50 \%$ of field capacity level. Data are means of four replicates each consisting of six grains from the middle part of each ear. Bars indicate SEM; open columns, control; solid columns, water stressed
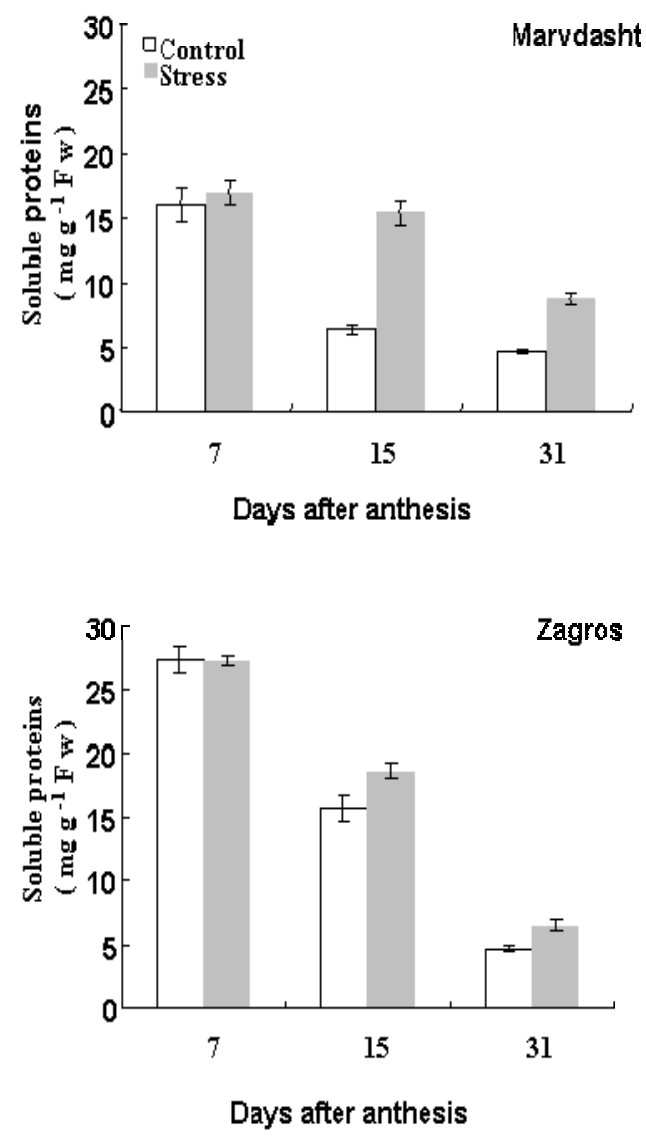

Figure 4. Effect of water stress on soluble proteins content of wheat grain. Water stress commenced at anthesis at $50 \%$ of field capacity level. Data are means of four replicates each consisting of six grains from the middle part of each ear. Bars indicate SEM; open columns, control; solid columns, water stressed 

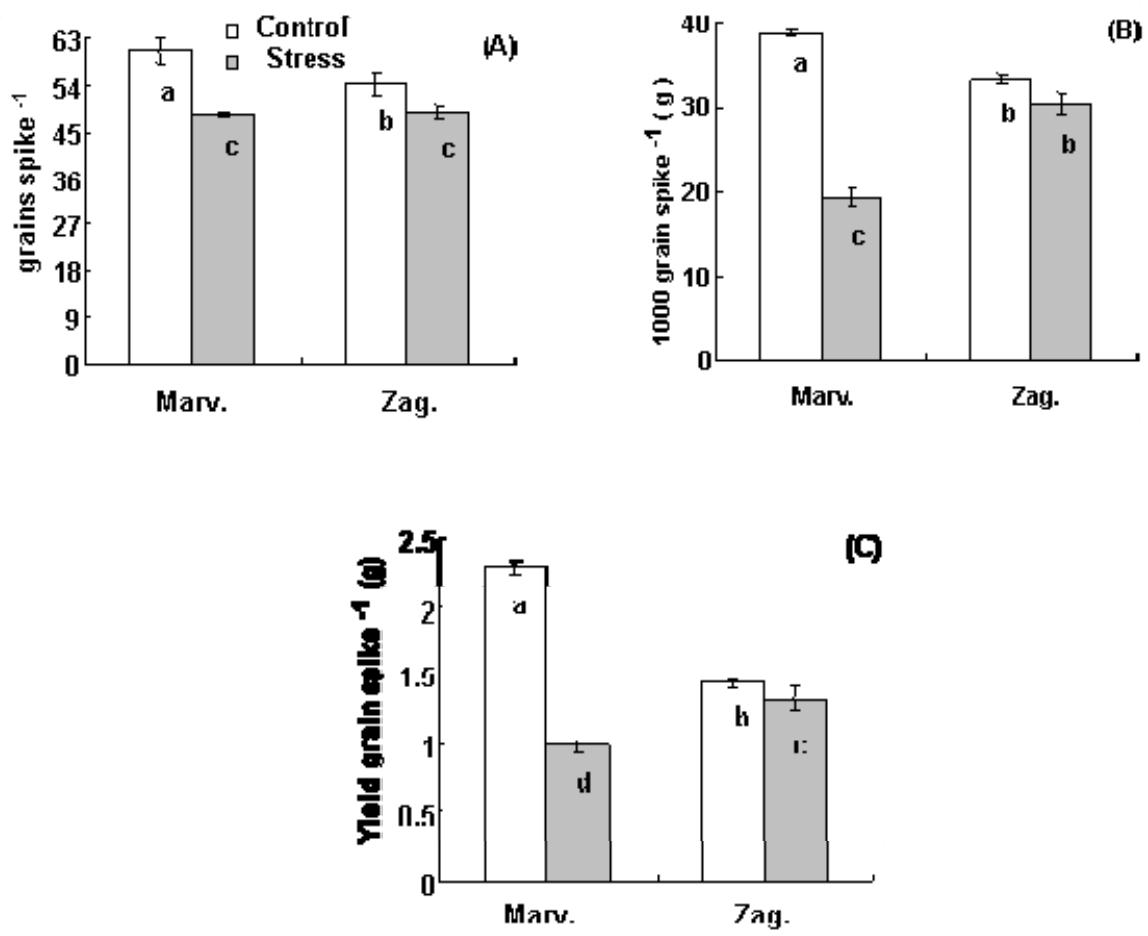

Figure 5. Effect of water stress on grain numbers per spike (A); grain weight (B) and yield grain per spike (C), of drought-sensitive (Marvdasht) and drought-tolerance (Zagros) cultivars. Water stress commenced at anthesis at $50 \%$ of field capacity level. Data are means of four replicates. Bars indicate SEM; open columns, control; solid columns, water stressed 